\title{
Service design as the service and social innovation for Shanghai urban mobility: An experimental project of "Smart Mobility"
}

\author{
Bo Gao / Tongji University / Shanghai / China \\ Kin Wai Michael Siu / The Hong Kong Polytechnic University / Hong Kong \\ Mingjie Zhu / Tongji University / Shanghai / China
}

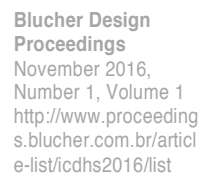

\begin{abstract}
Fast urbanization brings many challenges to the everyday life in Shanghai. There is a need of design for public service to improve the quality of urban life and providing ecological urbanism. After 20 years' development in China, service design has been recognized at the beginning to the public service and social innovation applications nowadays. This paper presents a jointed service design research and education project "Smart Mobility", which among three Asia design colleges. This paper is discussing around the application and practice of integrating service design thinking into enhancing the experience of urban mobility. After using the service design tools, the topic has been defined as how to make the auto-bus waiting time more interesting, and how to upgrade the experience of Shanghai Ferry. "HUXI" and "Art Stop" have been selected as the case study to explain the project approach and outcomes.
\end{abstract}

\section{Keywords}

Public service design, smart mobility, social innovation, service design education

\section{Introduction}

The research background

The imbalance of population distribution and the severe population aging have already brought pressure to city's resource supply and public service, such as public mobility service capabilities. In 2015, China's "Internett" strategy, which will integrate mobile internet, cloud computing, big data and modern manufacturing (Shan,2015). ICT Government will guide enterprises with proper subsidies and use the market mechanism to operate to promote the information technology projects to better benefit the residents. The new generation of telecommunications, computers and wireless devices again open up many possibilities. All these new technologies work as service enablers.

\section{Public transport services in Shanghai}

Shanghai is the largest Chinese city and the 10th largest city by population in the world, with population of more than 24 million as of 2013 (data source: shanghai government, statistics bureau). And in which there are 8.9 million migrant workers accounted $39 \%$ of all (data source: the sixth national census). Shanghai has extensive public transportation system, with developed MTR network containing buses, trolley buses, taxis, and a rapidly expanding metro system. According to the Shanghai Quality Association (2012), the Investigation is about what is important to improve satisfaction of Shanghai's public transportation. We can learn that $42.4 \%$ people think it is the reduction of public travel costs. $38.5 \%$ people think that it should accelerate the construction of flexible combined transport, and $36.1 \%$ people think it should improve good experience in service.

China's popular O2O On-Demand Transportation Startups - Didi Taxi, which makes it virtually impossible to flag down a taxi on the streets now. It has met the entry requirements to service the vast customer pool but the service is still one-dimensional so they must create a comprehensive service platform to connect the social innovation and business innovation as well. Service design has unveiled its inclusive features of cross-discipline, integration and humanity, as Parker and Heapy (2006) stated "the common challenge of service [is] in thinking about how to transform public services". Service design has been recognized from the business case applications at the beginning to the public service and social innovation applications in China. 
The "smart mobility" project, we discussed in this paper, was in connection with public transport services operated in Shanghai everyday. The project was aiming to formulate a localized approach in ICT (Information and Communication Technologies) based service. ICT-based service design can help expand the public transportation service areas, and in turn, build closer relationship between local citizens and new migrants, from technology but culture perspectives and social considerations. Meanwhile, the project is trying to explore service design education method in Chinese context.

\section{Research approach}

Traditional service provision is undergoing major transformations due to the infusion of technology into service encounters (Bitner et al., 2000). Services are usually developed in close interaction with the customers. Services are usually innovated in networks rather than labs (Abramovici and Laurence, 2004). ICT- based service innovation, which combined with the general liberalization of services in the 1990s, has transformed several industries, such as financial services, telecom and IT, and media (Bygstad and Lanestedt, 2009). ICT-based service including a set of information and digital technology tools. Technology is improving the ways in which impersonal services can complement or replace the human element in the process of service creation (Bitner et al,2000). It could include application to the following aspects of services: user interfaces, tangible artefacts integrated with services, service processes, usability, definition of desired customer experiences, processes for communicating with customers, community building and marketing materials. Following with the increasing importance of services and the importance of technological innovation, ICT-based service could contribute to the introduce innovation factors in public services, and explore various collaborative possibilities.

\section{ICT-based service introduces factors in public service innovation}

Service innovation can be defined as "a new or considerably changed service concept, client interaction channel, service delivery system or technological concept that individually, but most likely in combination, leads to one or more (re)new(ed) service functions that are new to the firm and do change the service/good offered on the market and do require structurally new technological, human or organizational capabilities of the service organization." (Johne and Storey, 1967) Most research on innovation still is in the high-tech products field (Tidd and Hull, 2003). There is that too little is known about ICT-based service innovation in public service.

The concept of service innovation will go beyond the physical geographic domain, and as an enabler, ICT-based service introduces commercial and social innovation factors to the public services. Didi ondemand transportation, Uber's Chinese version, is a typical commercial innovation example. The Internet is main driving force to transform many industries to focus on individual demands, thus ICT-based service has tremendous potential to bring value to these kind of start-up internet application platforms to conduct customer analysis and precise marketing, in order to help the senior people or visitors to get taxi services easily.

It is not that public services need to be more like commercial service providers. It is that all service organizations need to find new ways of connecting intimately with their users and customers, of listening and responding in ways that reassure us all that we are being understood (Parker and Heapy, 2006). ICT based service innovation presents another challenge; it usually redefines the roles of the service provider and the users. (Bendik et al., 2009) Not only just adopting traditional services design methodologies, but ICT based service will further apply interactive network applications to include as many stakeholders as possible and co-create the design models in every layer or activity. The intangible, quick-moving or fleeting service touch points needs to be tangibly, concretely and visibly displayed in front of the stakeholders. ICT-based service usually applies visualization technology to extend collaboration experience during the services, deepen collaboration acknowledgment after the services, and enhance collaboration relationship among stakeholders along the whole process. The way that all the stakeholders are not simply grouped as providers or receivers, but participants or players to collaboratively co-create, co-develop and co-design will make more significant sense particularly in public service sectors than others.

Tiramisu, as a good example of ICT-based service introduces factors in public services innovation. This app use of field trials to evaluate crowd-sourcing prototypes and on how crowd sourcing can generate coproduction between citizens and public services. Tiramisu's design integrates theories from service design on coproduction and co-design, with the intention of getting commuters to engage more deeply with the transit service and begin to feel they can influence its service offerings (Johne et al., 2011). 


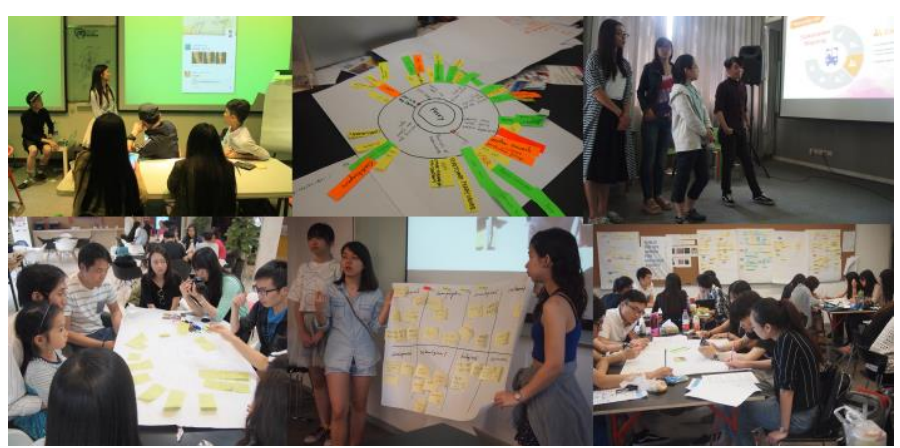

Fig. 1: The students adopted various service design research methods

\section{ICT-based service introduces in social innovation}

When public services take a more user-centered design approach, they often learn that their customers' main desires are for different services, not for automated services (Bradwell and Marr, 2008). In terms of ICT-based introduces in social innovation, socio-technological developments are changing our ways of communication and living and show possibilities that technologies can be used an enabling solution to promote social innovation

at the grassroots level (Baek et al., 2009). ICT-based service helps bottom-up participation to shift the power dynamics between customers and businesses from the social innovation point, and ways of communication and broadcasting between various social stakeholders to improve social network connectivity. Service design shall take advantage and further build up a more interactive-friendly platform to help proactively share working experience and manufacturing process.

With the development of online instant messaging tools, such as WeChat and Facebook, it provides infinitive possibilities to connect people at random if desired (if these are open to it) and integrate with social networking services. The production of a service and a social network is mutually beneficial and creates a virtuous cycle. The production of the two elements can be amplified by ICT. ICT-based service could change the role of citizens in society from only describing the needs, desires and expectations to acting as collaborative members in the design, production and provision of public services (Botero et al., 2012). Through adopting social networking software and official or unofficial meetings, organisations could facilitate the progress of the prototype implementation more effectively. (Wu and Sung 2014). There is a good practice project named" HealthConnect" in U.K. It is a service development proposal designed to improve access to health and social care services in Buckinghamshire. "HealthConnect" improving service of the transport to health and social care, for both urban and rural residents in the $50+$ age range.

Therefore, ICT-based service design research of this paper selected the topic of "Smart Mobility" as the experimental to put focus on the public transportation services in Shanghai, indicated how ICT-based service design can improve public service and drive social innovation.

\section{Project approach and outcomes}

"Smart Mobility" as the ICT-based service design research project was carried out jointly by Tongji University from Shanghai, The Polytechnic University Hong Kong and Sungkyunkwan University from Seoul. The project planned four design works to cover the most critical issues and touch-points that people might encounter when taking public transportation. Service design provides tools for user engagement in public services (Parker and Heapy, 2006) Students exploring service demands that stem from people's ever-lasting pursuit of personalized mobility in Shanghai, and formulating customer-friendly and inclusive design schemes in response. They adopted various service design research methods, such as field research, interview, co-design, rapid-prototype, customer journey and so on. Finally,

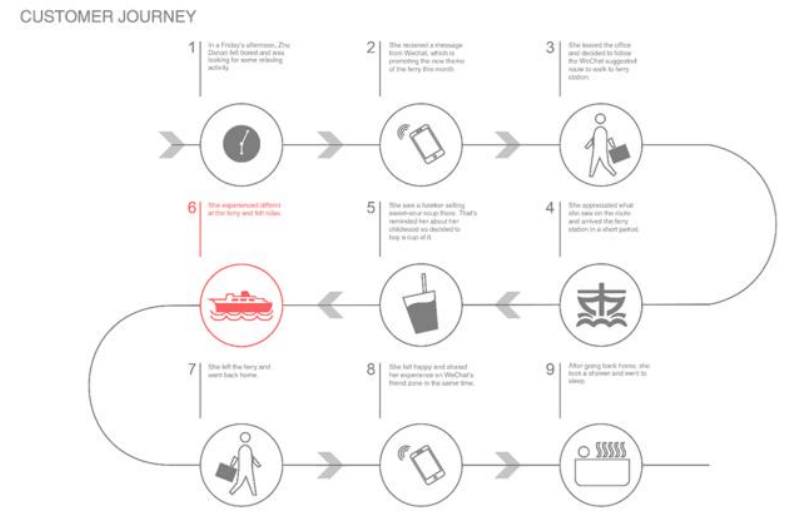

Fig. 2: The customer journey and the prototype of "HUXI" O2O system four design works were developed. The "HUXI", was to create five-minute slow-life experience for urban whitecollar when taking Shanghai ferry. The second work, "Art Stop", was to the communication innovation via using the social network to make the bus-stop waiting time more interesting with performing arts. The third work, "LBS (Love Bus Stop)", was to provide convenience for the elders who does not live close to the public transportation. And the fourth work, "Know How", was the $\mathrm{O} 2 \mathrm{O}$ service system to engage the community residents to tourist services. During the field research approach, which included the face-to-face interview with focus group and recorded all the segments randomly. We insisted to find 
the valuable information by face-to-face interview, watching what people don't do, listening to what they don't say (Brown, 2009). During the field research approach, the discussing group in Wechat were built as social networking platform, where a group of designers, local practitioners, researchers, and stakeholders can freely discuss and sharing the updating information about the topic. We choice "HUXI" and "Art Stop" as the case study.

\section{Case study 1 - HUXI}

The research group focused on the traditional ferry services in Shanghai. A century ago, the Shanghai Ferry was known as the only option to travel across the Huangpu River, from Pudong to Puxi, and claimed to be the world's busiest at that time. However, few people take ferry nowadays. After the field researcher circulated questionnaires on street to 60 people randomly, 54 collected response told us that only $1 \%$ of people would go by ferry, and surprisingly majority of people don't even know the ferry services are available transportation choice. The reasons we found out were mostly because the poor quality of ferry services. When the quick and easily reachable metro services were developed, people began to ignore the ferry. As an important historical transportation, Shanghai ferry needs to rejuvenate to provide brand new commuting experience.

The research group went to 4 ferry stations to interview the passengers, the staff and the managers. The passengers considered safety as a problem because the ships had been operated basically over 20 years. A severe accident happened in 1987 with 66 people died in stampede at Lujiazui Dock. The manager of the Shanghai ferry emphasized to add some entertaining elements and promote the historic values. Identification of innovative customers who are likely to be most helpful during new service development (Rogers, 1995 and Hippel, 1988). The research group outlined the target ferry takers who are the young white-collar working in the Pudong financial district since they are very close to the ferry and have willingness to experience new services. They also required high standard of comfort and convenience.

"HUXI" means breathe in Chinese, which explains the main design idea of taking a break and refreshing. It was a good idea to add some entertaining elements and promote the historic values of Shanghai ferry in the 10-min journey to help white-collars release working pressure and enjoy slow-life cultural atmosphere via ICTbased service. In "HUXI" design work, the stakeholders identified included ferry takers, ferry operating company, advertisement provider, groceries and broadly Shanghai citizens. The new customer journey for the innovation customers: By scans the QRCode, the target user can receive a message about the new theme of Shanghai ferry from the subscription. By follows the route recommended by the subscription, user can have a peaceful riverside amble before arriving at the ferry station. By improving the wicket the tunnel and the ferry interior, and providing a special drink, which is different offered by different theme selling with the ferry ticket, to provide a new ferry service experience. First of all, WIFI must be available in the ferry station and ships to let people connected via internet. With the WeChat tool, the target ferry takers would have a new customer journey by scanning the QR Code, receiving messages about Shanghai ferry service schedules, events and discounts. The high-resolution projectors needed to be installed to play music videos during the dull waiting time, creating a private peaceful moment for the white-collars to release pressure on the ship. People could also choose to stand outside at the board to chat with other passengers. Before, during and after the "HUXI" journey, ferry takers could share their experience in the social media which will lift the ferry services as important as metro and bus.

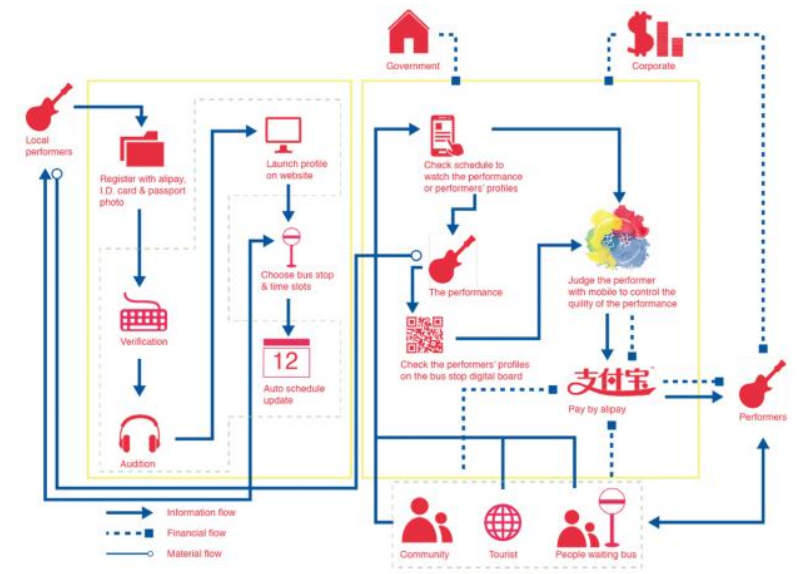

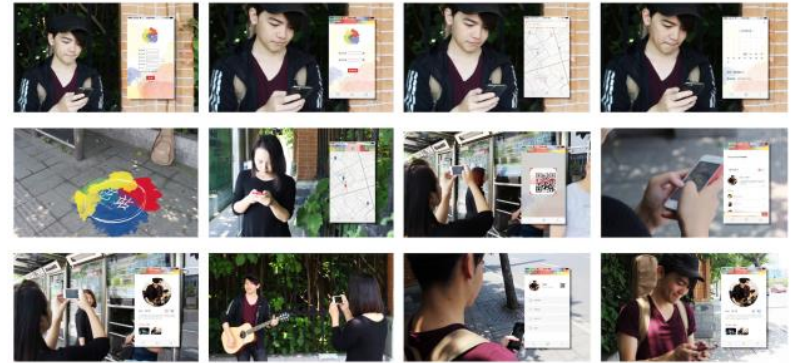

Fig. 3: The customer journey and the prototype of "Art Stop" $\mathrm{O} 2 \mathrm{O}$ system 


\section{Case study 2 - Art Stop}

After the field researching, the research group focused on the bus waiting time and city's street performers. They had stayed to observe around the bus stations along the streets for hours. 40 questionnaires were distributed and collected from bus passengers, and furthermore another 10 in-depth interviews were conducted both in subway and at bus stops. The community closed to bus station were invited to join and co-design. The key findings included that people might take bus if bus stop is in walking distance $(<500 \mathrm{~m})$; people would feel boring and impatient when waiting time is more than 10 minutes, and feel fretful if more than 35 minutes. People didn't have much to do during the waiting time. At the same time, street performers usually gathered at public places to show their talents. Metro stops, bus stops or park entrances were their performance stages. But sadly street performers were frequently driven away by the police or urban supervisory officers. Street performers were tend to been treated as beggars or homeless in China. When we looked outside in Europe, Japan as well as India, street performers were treated as the vagabond artists and allowed to do creative shows in public spaces. The London Underground provides busking permits in tube stations. For many musicians, street performance was the most common means of employment before the advent of recording and personal electronics (Broad, 2014).

The experiences of bus services depend on a variety of non-instrumental factors such as cleanliness, privacy, safety, convenience, social interaction and scenery (Stradling et al., 2007). The social interaction during the waiting time is the key in this project. The mission of the design work was to create an $\mathrm{O} 2 \mathrm{O}$ (online to offline) public service system to improve bus taking experience, and create a new $\mathrm{O} 2 \mathrm{O}$ social space to connect people. More stakeholders have been involved in this $\mathrm{O} 2 \mathrm{O}$ service system, such as the street performers, the passengers, the bus company, which were the sponsors supporting the event and getting profits from ads. An event deviating from customers' expectations, and the memory of frequently experienced incidents have an impact on customers' service experiences with the public transportation offering (Friman and Garling, 2001). The customer journey including :signing in the app; printing ID card number to ensure that user is the exact person to guarantee the authority and safety of app; the user can apply for a performance and wait for permission; potential audience can search the information of performances; the users can choose it on map or by scanning QR code on the station. The performers were designed to stand inside the "Art Stop" waiting zone on the floor near bus stop, to avoid disturbing traffic and other passengers. Audience can give like or dislike or commends to the performers in the "Art Stop" mobile app. In addition, it is able to send the instant notice of the coming bus so that the passenger would not miss their bus trips. The passenger feedback would be one of the effective appraisal channels to evaluate the quality of performances. If the performances were in high quality, besides giving performers like or unlike or some commends, passengers or even community residents can also financially support the performances by using payment tools in the "Art Stop" mobile app. Of course, the street performances and the events could be promoted for financial sponsors as well. To control the quality of performances, besides giving performers like or unlike or some commends, passengers or even community can also pay for the performances by alipay. Also, performers and the whole event can be supported by sponsors.

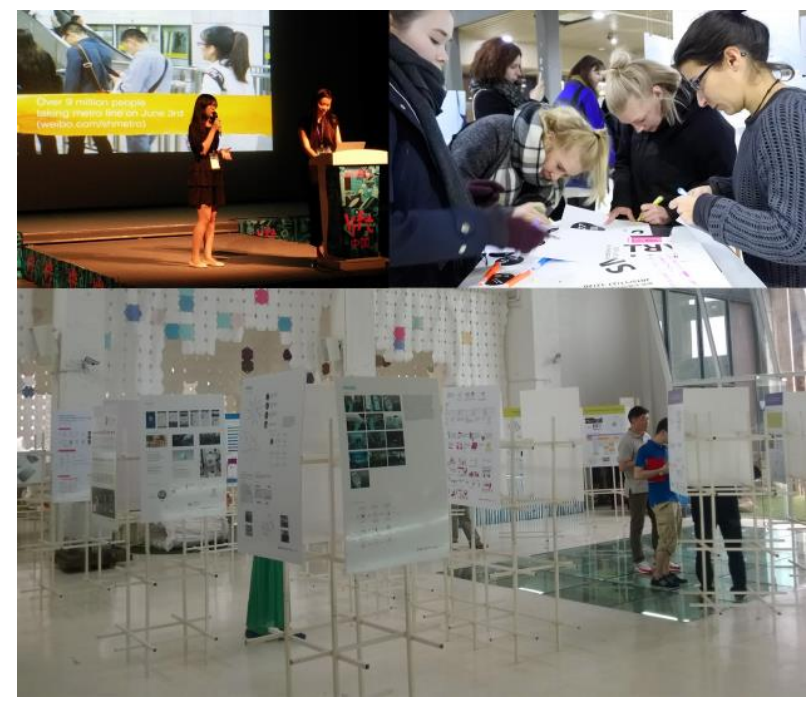

Fig. 4: The research group got good feedback from some exhibition visitors and design conference audios

\section{Conclusion}

"Smart mobility" project was the experimental project, among the first attempt to solve the issues related to public service sectors, though there needs to develop more China specific and innovative approaches to fit the local complexities. The international research team has been also encouraged by the development of the latest information technology that a few big data platforms entered into commercial operations which enable us to dive deeper in behavior analysis for customer experience exploring. Though this is among the first attempts to solve the issues related to smart transportation by ICT-based service design, we have got good feedback from some exhibition visitors and design conference audios. Our future research will pay more focus on the big data technology to articulate the social transition dynamics. The working group have mind to 
validate and optimize our service design approach against the feedback along the way going forward, and bring up our study on the prototype of the diversified service innovation as our project subjects in next phase.

Public services are not fancy concepts but those basic topics around people's day-to-day living behaviors. Service design, as human-centered design approach, has to put more value in people's life experience than commercial or technic considerations. The nature of the public service design is to achieve fairness and sharing. ICT-based service makes services more accurate with technical means to deliver the benefits to the stakeholders. It also provides the possibility to grant different roles for the urban residents in one service scenario, could be both public service receiver and service provider at the same time, which effectively mobilize the residents' sustainable well-being enthusiasm.

\section{Acknowledgements}

The research was sponsored by the Chinese National Social Science Fund of the Ministry of Education. (14YJC760011) and Chinese Fundamental Research Funds for Central Universities. The Public Design Lab of The Hong Kong Polytechnic University also gave partial research support.

\section{References}

Abramovici, M., \& Bancel C. L. (2004) 'How to take customers into consideration in service innovation projects', The Service Industries Journal, 56-78.

Baek, J., Manzini, E., \& Rizzo, F. (2009) 'Sustainable collaborative services on the digital platform: Definition and application', Retrieved January 13, 2016, from http://www.researchgate.net/publication/262804513_Sustainable_collaborative_services_on_the_digital_pla tform_Definition_and_application

Bitner, M., Brown, S., \& Meuter, M. (2000) 'Technology Infusion in Service Encounters', Journal of the Academy of Marketing Science, 138-149.

Botero, A., Paterson, A.G., \& Saad-Sulonen, J. (Eds.) (2012). Towards peer production in public services: Cases from Finland, Helsinki: Aalto University.

Bradwell, P., \& Marr, S. (2008) Making the most of collaboration an international survey of public service co-design. London: Demos.

Broad, N. (2014) The Busking project support. Retrieved January 13, 2016, from https://busk.co/support Bygstad, B., \& Lanestedt, G. (2009) 'ICT based service innovation - A challenge for project management', International Journal of Project Management, 234-242.

Chih,S.W., Tung,J.S. (2014) 'Stakeholder Involvement and Co-Creation in Service Design: Customer experience management in tourism', 19th DMI: Academic Design Management Conference Design Management in an Era of Disruption.

Djellal, F., \& Gallouj, F. (2001) 'Patterns of innovation organisation in service firms: Postal survey results and theoretical models', Science and Public Policy, 57-67.

Friman, M., Edvardsson, B., \& Gärling, T. (2001) 'Frequency of negative critical incidents and satisfaction with public transport services', Journal of Retailing and Consumer Services, 95-104.

Grönroos, C. (2000) Service management and marketing: A customer relationship management approach, $2^{\text {nd }}$ edition, Chichester: Wiley.

He, S. (2015) 'Internet Plus' strategy gives impetus to Internet firms', Retrieved January 13, 2016, from http://www.china.org.cn/china/NPC_CPPCC_2015/2015-03/12/content_35030933.htm

Hippel, E. (1988) The sources of innovation. New York: Oxford University Press.

Huxham, C., \& Vangen, S. (2005) Managing to collaborate: The theory and practice of collaborative advantage. London: Routledge.

Johne, A., \& Storey, C. (1967) 'New service development: A review of the literature and annotated bibliography', European Journal of Marketing, 184-251.

Nroos, C. (2000). Service management and marketing: A customer relationship management approach, $2^{\text {nd }}$ edition, Chichester: Wiley.

Parker, S., Heapy, J., \& London, E. (2006) The journey to the interface: How public service design can connect users to reform. London: Demos.

Rogers, E. (1983) Diffusion of innovations, 3rd ed. New York: Free Press.

Stickdorn, M., \& Schneider, J. (2011) This is service design thinking: Basics, Tools, Cases. New Jersey: Hoboken.

Stradling, S., \& Anable, J. (2007) 'Performance, importance and user disgruntlement: A six-step method for measuring satisfaction with travel modes', Transition Research Part A: Policy and Practice, 41 (1), 98-106.

Tidd, J. (2003) Service innovation organizational responses to technological opportunities and market imperatives. London: Imperial College Press.

Zimmerman, J., Tomasic, A., Garrod, C., Yoo, D., Hiruncharoenvate, C., Aziz, R., . . Steinfeld, A. (2011) 
' Field trial of Tiramisu: Crowd-Sourcing Bus Arrival Times to Spur Co-Design', Proceedings of the 2011 Annual Conference on Human Factors in Computing Systems - CHI '11. Feb 1999].

\section{Biographical note}

Gao Bo is the associate professor of teaching and researching on service design, information and media design, sustainable design in the College of Design \& Innovation, Tongji University. Dr. Gao published numbers of academic paper in international conferences. She is an active member of DESIS China and LeNS -China.

Kin Wai Michael Siu is Chair Professor of Public Design, School of Design, The Hong Kong Polytechnic University. He is Founder and Leader of the first Public Design Lab. He is Leader of Research Group for Sustainable Public Design of the RISUD. He teaches design and engineering subjects and supervises postdoctoral and $\mathrm{PhD}$ research.

Zhu Mingjie is a PhD candidate from the College of Design and Innovation, Tongji University and School of Design, The Hong Kong Polytechnic University. Her research interest is social innovation design especially in urban community and public space. She has published several related articles in international conferences. 